\title{
Development and Application of Network Teaching System of Machine Design Foundation
}

\author{
Yunfang Xie ${ }^{1, a}$ \\ ${ }^{1}$ Nanjing Vocational Institute of Technology, Nanjing 210046, China \\ aemail: xieyf@niit.edu.cn
}

Keywords: Network Teaching; Remote Assistance; Machine Design Foundation

\begin{abstract}
In order to realize the interactive teaching of the course of Machine Design Foundation, we use the campus network and computer aided design software to construct the network teaching platform, this platform consists of three modules, which are interactive teaching module, teacher management module and system management module, the advantage of this platform is that it can realize remote assistance function in mechanical drawing design according to the characteristics of this course. It can improve the communication ability between teachers and students in the premise of ensuring the sharing of resources.
\end{abstract}

\section{Introduction}

The Machine Design Foundation is an important practice course, plays an important role in cultivating students' comprehensive ability and engineering consciousness, innovation ability etc. ${ }^{\text {[1] }}$ This course of general mechanical transmission device is cylindrical gear reducer as a design, because the reducer design basically includes all the main content in the course of mechanical design, including the design of task analysis, transmission scheme and transmission device design, parts design calculation and selection, assembly drawing and parts drawing and write a design calculation manual etc. ${ }^{[2]}$

With the development of modern information technology, the computer's popularization, social requirements greatly to improve the teaching quality and teaching efficiency require schools. Rich existing learning resources, create personalized learning environment is the requirement of individualized teaching theory, is the development of the times and social progress, so the realization of personalized, interactive teaching is the main direction of network teaching reform. ${ }^{[3]}$ [4]

Therefore, the system research is on the perfection of the campus broadband network hardware foundation, combined with the open web technology, collaborative design technology, construction of remote collaboration and interactive graphics functions of mechanical design teaching system. In the design and development, according to the characteristics of the graphics is the main part of the Machine Design Foundation of attach importance to practice, pay attention to creative, combined with CAD application software, to achieve the Machine Design Foundation graphics online browsing and remote assistance function, provide strong support for the assistance of the teachers and students learning. ${ }^{[5]}$

\section{Meaning and characteristics of interactive network teaching mode}

Network teaching refers to the computer network, satellite communications network and telecommunications network for the media, teaching and learning activities in the multimedia network course is the core of the network environment in the form of organization. ${ }^{[6]}$ Interactive network teaching is different from the traditional teaching, but also to single audio-visual teaching. It is based on a full respect for science teaching rules and students' personality development needs on the basis of teaching mode, learn from teacher centered and the network system for the advantages of two types of teaching modes on the center, so that the advantages of complementary. This kind of teaching mode for students to provide images, text and audio-visual articles interactive 
human-machine interface, with human associative thinking and associative memory characteristics, according to the super text structure organization of large-scale knowledge base and information base, the formation of human-computer interaction, teacher-student interaction, students interaction, resource sharing, complementary advantages of comprehensive teaching mode, for learners to achieve exploration and discovery learning to create favorable conditions. ${ }^{[7]}$

\section{Development and design of the system}

\subsection{Development environment and mode of system}

This system of the teaching platform is implemented in the Internet environment, using B/S (Browser/Server) network development model. In the development of B/S network mode, the client only need to install the browser and operating system, the network protocol can, all application software development, maintenance and upgrade work undertaken by the server. This system is developed on Windows platform, using Microsoft SQL and ASP.NET Server2000 database programming language. Client to access the system through a browser to provide the service, the system does not allow anonymous access, it requires the user to provide a user name and password, and the verification can enter the relevant operation, in order to track the user's identity. In this system, students can view the client information in the database and download and curriculum related information, also can ask questions to the teacher. Teachers can update the database at any time, answering questions, while achieving graphics in mechanical design modification.

2.2 Design of the overall framework of the system

The main function of this system includes all kinds of reducer parts, browse and select the gear reducer design steps, query and calculation of students to design graphical browsing and modifying, answering discussion and other functions. This system is mainly to provide a network platform for curriculum design and communication of the students, so follow the principles in the design of the system are as follows: In the student interface, students can construct the independent design and learning environment, and teachers in the interface, teachers can design the deceleration required for students to upload material. Real time and non-real time guide and help the students of curriculum design, and through AutoDdesk's VoloView3.0 control graphics curriculum design in the Web browsing, modify and annotation. Flow chart of the system is shown in figure 1.

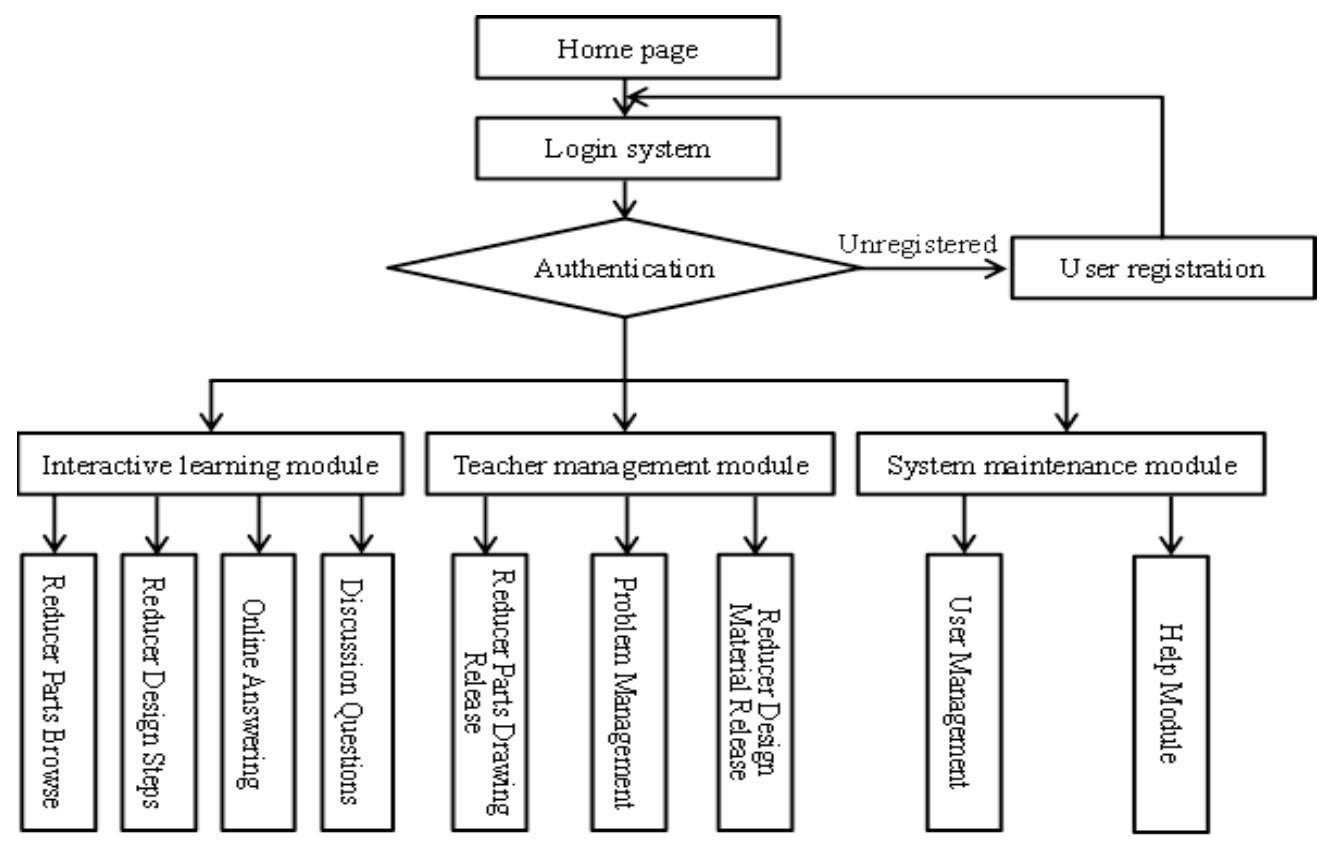

Fig. 1 The flow chart of the system

\subsection{Login and remote assistance}

Three status log on the system are administrators, teachers and students, representing three different permissions. When the three landing from the data table out of the user name and 
password, verification, according to the user name and user groups of different, to determine their proper permissions. When the user name is Admin, the identity of the administrator, directly into the administrator interface, When the user name is not Admin, and usergroup=2, the user identity as a teacher, to enter the teacher operating interface, and usergroup $=1$, the user for student users, access to the user interface.

The realization of remote assistance is embedded in the system Windows XP "remote assistance" control or Tencent and other software. When students need help in the design, the local area network can send mail or use Tencent software to apply for assistance. After the application has been confirmed, the teacher can through the Internet remote control students computer, through the transmission of voice and video information to help students in retarding the problems encountered in the design, like face-to-face instruction.

2.4 Interactive learning module

Interactive learning module is the designer query reducer design process, the exchange of ideas and questions of the place. This module mainly includes: the design of reducer, reducer parts step query browsing area, online answering area and the discussion area.

In reducer design steps of the query region, students according to their design tasks according to the system prompt, deceleration transmission device of the overall design, such as: determine the transmission scheme, selected motor model, rational allocation of transmission ratio and calculation of kinematic and dynamic parameters of the transmission device. Then, according to the system, the design and calculation of the transmission parts of the reducer are carried out. According to the results of course designers can design the transmission components, the reducer parts determine the browsing area structure and size of parts required.

Online FAQ district by the teachers to organize students to participate in real-time. On the basis of text and speech communication, the module mainly realizes the function of on-line real-time browse, edit and remote network assistance. Because the mechanical two-dimensional graphics and AutoCAD software graphics standard is compatible, but the AutoCAD software graphics and cannot be directly displayed in the browser. Volo view therefore, this module using Autodesk released browser control, and is registered in the web server, user can use the Internet to CAD graphics to achieve the basic move, zoom, and annotation functions through the control of secondary development.

Chat rooms in the area are mainly used for synchronous communication, can be designed in real time to discuss the content, but also in the teacher or leader of the organization held a regular meeting of the network. The content of the speech can be recorded by the system for future browsing.

2.5 Teacher management module

The main function of the teacher management module is the release of the teaching resources and the management of the students' problems. Including: various types of reducer parts release area, the issue of the management area and the design process of the release of the release area.

All kinds of reducer parts release provided to teachers in the management of the backstage entrance, teachers through the entrance can will show different types of parts, so that the students can in any time log in to the web site, and according to the transmission parts of the design calculation results to determine the parts of the structure and size.

In the problem management area, in order to be able to attract the attention of students, teachers will be prone to errors in the course design of the students in a dynamic way to show up in the web page.

In the resource area, teachers provide guidance materials, design cases, speech records, results, etc., and management of these resources. Using this module, teachers can modify, delete, write online, upload attachments and other operations, students can browse, review, download, upload, and search related teaching resources.

2.6 System management module

System management module provides user management and use of the system to help. User management module can provide users with different registration, landing rights management. The 
system will be divided into three types: teachers, students, administrators, respectively, with different permissions. The administrator has the highest authority, the system can be managed, can also participate in the construction of knowledge base, teachers mainly involved in knowledge base construction, can also be made of the student answer, students can learning websites provide the resources can also be mutual discussion or ask questions to the teacher.

Help module provides the system using the help and guidance of learning strategies of publishing, browsing and retrieval, help guide and real-time warning. Help information can set different guidance range, including public information, group information, help to help individuals to help information, to show the different users.

\section{Concluding remarks}

Interactive network teaching can not only spatial practices and flexible advantage, but also conducive to the development of a variety of interactive activities, can better to make up for the defect of the lack of communication between teachers and students in traditional education, especially in the cultivation of students' innovation ability and personality development reached a significant effect. The design of network teaching system based on campus network, constructing the network teaching platform, greatly enrich the teaching resources, curriculum design.

This system mainly realizes the following functions: (1)Completed the Machine Design Foundation in the release of the design content, issues management, knowledge and other functions, (2) Through the Internet network, the teacher to the student's remote assistance function is realized, (3)The realization of the Machine Design Foundation in the graphics online browsing and editing functions. The system expands the channels of learning, which is convenient for teachers and students to learn, and plays an important role in cultivating students' comprehensive quality, and has been praised by teachers and students.

\section{References}

[1] Lu B, Qian Y X, Liu J J. Independent Innovation Network Teaching Platform Research [J]. Advanced Materials Research, 2012, 468-471:1899-1902.

[2] Liang X D. The Design and Implementation of Mutual-Help Teaching System Based on Multimedia Network [J]. Procedia Environmental Sciences, 2012, 12(1):1231-1236.

[3] Zhuang Y. Exploration of "Machine Design Foundation" teaching in Higher Vocational College [J]. Science Education Article Collects, 2011.

[4] Li X H. The Discuss on the Machine Design Course Teaching Method[M]// Informatics in Control, Automation and Robotics. Springer Berlin Heidelberg, 2011:671-675.

[5] Gao Y B, Hui-Li Y U. Exploration and practice about experiment teaching of machine design foundation [J]. Laboratory Science, 2010.

[6] Song Z H, Cao Y. Reform on the Teaching of 《Machine Design Foundation》[J]. Journal of Taizhou Polytechnical Institute, 2006.

[7] Xie J, Song Z H, Zhang B. Teaching Exploration on the High Vocational Machine Design Foundation [J]. Journal of Taizhou Polytechnical Institute, 2007. 